\title{
Estimating the Net Effects of Migration and Remittances on Poverty and Inequality
}

\author{
Comparison of Fiji and Tonga \\ Richard P. C. Brown and Eliana Jimenez*
}

April 2007

\begin{abstract}
We use original 2005 household survey data from Fiji and Tonga to estimate the impact of migration and remittances on income distribution and measures of poverty, after controlling for selectivity in migration and endogeneity in the relationship between remittances and income. Measures of inequality and poverty based on actual, with-migration income and remittances are then compared with those based on a no-migration scenario. Counterfactual household incomes are estimated, taking account of what the migrant members would have earned had they not migrated. The results are compared with alternative income estimates in which remittances are treated simplistically as exogenous transfers. The positive effects of migration and remittances on poverty alleviation and income distribution are found to be stronger when the more rigorous, counterfactual income estimates are used.
\end{abstract}

Keywords: migration, remittances, income distribution, poverty, Fiji, Tonga

JEL classification: F22, F24, I32, O15

Copyright (C) UNU-WIDER 2007

* School of Economics, University of Queensland, Brisbane; corresponding author: r.brown@economics.uq.edu.au

This study has been prepared within the UNU-WIDER project on Fragility and Development, directed by Mark McGillivray and Amelia Santos-Paulino.

UNU-WIDER gratefully acknowledges the financial contributions to the project by The Australian Agency for International Development (AusAID), the Finnish Ministry for Foreign Affairs, and the UK Department for International Development-DFID.

UNU-WIDER also acknowledges the financial contributions to the research programme by the governments of Denmark (Royal Ministry of Foreign Affairs), Norway (Royal Ministry of Foreign Affairs), and Sweden (Swedish International Development Cooperation Agency-Sida.

ISSN 1810-2611 ISBN 92-9190-962-9ＩSBN 13 978-92-9190-962-9 


\section{Acknowledgements}

We thank the World Bank for permission to use the data from a recent survey funded by the Bank (see Brown et al. 2006), John Connell, Gareth Leeves co-researchers on the World Bank study, and Chris O’Donnell for his help in modelling migration and remittances in this paper. We also thank participants of the UNU-WIDER December 2006 meeting in Fiji on Fragility and Development for their useful comments on an earlier draft of this paper.

The World Institute for Development Economics Research (WIDER) was established by the United Nations University (UNU) as its first research and training centre and started work in Helsinki, Finland in 1985. The Institute undertakes applied research and policy analysis on structural changes affecting the developing and transitional economies, provides a forum for the advocacy of policies leading to robust, equitable and environmentally sustainable growth, and promotes capacity strengthening and training in the field of economic and social policy making. Work is carried out by staff researchers and visiting scholars in Helsinki and through networks of collaborating scholars and institutions around the world.

www.wider.unu.edu

publications@wider.unu.edu

UNU World Institute for Development Economics Research (UNU-WIDER)

Katajanokanlaituri 6 B, 00160 Helsinki, Finland

Typescript prepared by Liisa Roponen at UNU-WIDER

The views expressed in this publication are those of the author(s). Publication does not imply endorsement by the Institute or the United Nations University, nor by the programme/project sponsors, of any of the views expressed. 


\section{Introduction}

This paper addresses the impacts on poverty and income distribution of migration and remittances in two Pacific island countries, Fiji and Tonga. The analysis is based on household survey data collected by the authors as part of a World Bank study in Fiji and Tonga during 2005 (Brown et al. 2006). This focus is motivated by a concern among policymakers that migration opportunities could be biased towards wealthier and bettereducated households with easier access to international networks, with the resulting inflows of remittances being more likely to reinforce existing inequalities than reduce them. More specifically, the study estimates the impacts of remittances on income distribution (Gini coefficients) and on the incidence and depth of poverty (poverty headcount and poverty gap ratios). The paper does not address the causes, effects and more general socioeconomic dimensions of poverty and hardship in the South Pacific. 1

The primary challenge of this research is to assess the combined effects of outmigration from these countries and the return flows of remittances, taking into account that remittances cannot be treated simply as an exogenous addition to household income. This paper recognizes that had the migrant household member not migrated, he/she would have contributed to household income, and, the number of domesticallyresident household members would be greater. The task before us then is to estimate what the household's per capita income situation would have been in the absence of migration - the counterfactual income level-and then to compare that with actual household per capita income with remittances included as part of total income. Previous studies of migration and remittances in the South Pacific have neglected this issue, choosing instead to treat remittances as an addition to what the household would have otherwise earned. In other words, rather than estimating a counterfactual without migration and remittances scenario, previous studies have simply compared actual income excluding remittances with income including remittances. This could result in an overestimation of the impact of remittances on both the level of household income (and poverty alleviation) and the distribution of income. In this paper we compare the results following both methodological approaches, allowing us to estimate the extent of over- or under-estimation of these impacts in previous work, including Brown et al. (2006).

Section 2 discusses previous research on measures of income distribution and poverty in Fiji and Tonga, while a review of the existing literature on migration, income distribution and poverty in other countries is presented in section 3. The 2005 survey and data for Fiji and Tonga are discussed briefly in section 4. We use these data to estimate migrants' counterfactual income which is then imputed into migrant households' income to derive the counterfactual household income against which we then compare actual household income with migration and remittances (section 5). With these estimates we are able to make comparisons of income distribution and poverty with and without migration and remittances. The results of our findings are then compared with: (i) the results that would have been found had we treated remittances simply as an exogenous addition to household income; (ii) the estimates of poverty and income distribution from other studies of Fiji and Tonga, including those which

1 For recent analyses of poverty and hardship in the South Pacific more generally, see Abbott and Pollard (2004); Walsh (2002); AusAID (2006: ch. 3). 
estimate the impacts of remittances; and, (iii) studies of the impact of remittances on income inequality and poverty in other countries. In section 6 conclusions are drawn.

\section{Previous research on Fiji and Tonga}

\subsection{Migration histories}

The choice of Fiji and Tonga as country studies for the World Bank study (Brown et al. 2006) was motivated by their different migration histories and remittance behaviours. Tonga, with over 40 years of intensive remittances-motivated migration, receives much larger per capita remittance flows and is more comparable to Samoa. In the case of Fiji, international migration is a relatively more recent phenomenon, but there are also important differences in migration histories between the two main ethnic groups, Indoand Indigenous-Fijians.

Recent circumstances in Fiji emphasize and dramatize the 'outward urge' that has become so powerful in the region. By contrast in Tonga there is no real evidence of any significant changes in the structure and impact of migration in the past decade. Fiji by contrast represents a country where migration and remittances have grown in significance, as has the awareness of their importance on the part of the government and financial sector.

A distinctive feature of international migration in the Pacific is that migrants have typically tended to be settlers, rather than temporary migrants, even though they may express (and sometimes act on) intentions to return home. Permanent migration is particularly true of many migrants from Fiji (mainly Indo-Fijians) and especially Tonga. This limits direct comparisons with other migration-remittance states, such as the Philippines and Pakistan, where most migrants are on short-term contracts. In recent years there has been a growing demand for more temporary, contract migrants, primarily from Gulf countries, which have been attracting growing number of temporary migrants from Fiji, mainly Indigenous-Fijians, and from growing labourmarket pressures for short-term contract labour migration from the Asia-Pacific region to Australia and New Zealand for both skilled and unskilled work. It is in this context that the potential economic benefits from remittances need to be assessed.

So substantial has international migration become that as many as a third of all households in Fiji had at least one overseas migrant (compared with 60 per cent in Tonga), and 43 per cent of households received remittances (compared with 90 per cent in Tonga). This is a remarkably high percentage after a relatively short period of engagement in international labour migration, and already reflects the substantial presence of Indigenous-Fijians in the security industry in the Middle East. Moreover, Indo-Fijian households are also remittance recipients contrary to earlier beliefs that few received remittances (Stanwix and Connell 1995; Connell and Brown 2005). It has been stated that the earnings of 250 Fijian soldiers working in Iraq for a UK security company totalled nearly US\$3 million in a six-month period in 2004-5 with all that pay being sent back to bank accounts in Fiji. Other estimates in 2005 suggested that remittances to Fiji would reach about US\$200 million for that year, well up from the US\$30.3 million in 2002, but consistent with our estimate for 2004 of US\$130 million (Brown et al. 2006). In Fiji therefore-even in the last three years-there has been 
explosive growth in the extent and significance of both migration and remittances, and some of these impacts are assessed in this paper.

Migration has reduced the level of open and disguised unemployment in the migrantsending countries although there is also a growing concern that it has contributed to a loss of skilled human resources, through 'brain-drain'. It is also believed that professionals and skilled workers are more likely to migrate following political or other social problems as appeared to be the case in Fiji following the military coups in 1987 and 2000 .

\subsection{Income distribution}

There is conflicting evidence in the literature on the impact of remittances on income distribution, with some finding that remittances improve distribution while others find that they reinforce existing inequalities. The reason often advanced is that the impact evolves over time. In the earlier stages of a country's migration experience, there is often a self-selection bias, with migrants not being randomly distributed across all income groups. It is usually argued that in the early stages migrants are more likely to come from the more prosperous households who are more able to take on the risks associated with migration, and with the ensuing remittances acting to reinforce existing income differences. But, as migration networks develop and migration becomes more widespread among all income groups, income distribution can be improved by migration and remittances, with remittances to lower-income households likely to be relatively much larger in relation to income from other sources. The early migration and remittances literature on the South Pacific tended to stress the negative impact of remittances on income inequality, with most observers noting that migration remittances were associated more with relatively well-off households (Shankman 1976; Connell 1981).

\section{Tonga}

The first attempt to formally quantify the impact of remittances on income distribution in the South Pacific was Ahlburg's (1991) study of Tonga and Samoa (Western Samoa at that time). Following what was then the conventional approach, treating remittances as an exogenous addition to household income, he uses 1984 Tongan household level income data to compare the share of income (excluding remittances) going to the poorest 20 per cent and richest 20 per cent with their respective shares of total remittances received. He concludes that the poorest households received 6 per cent of non-remittance income but 18 per cent of remittances, and the richest households received 43 per cent of non-remittance income but only 29 per cent of remittances, thus concluding that remittances improved income distribution.

The first attempt to compare Gini coefficients with and without remittance income is an ILO study of Tongan and Samoan remittances by Brown and Connell (1993). Using 1992 household survey data they find that remittances improved income distribution in both countries. The Gini coefficient in Tonga improved from 0.434 without remittances to 0.383 with remittances, and in Samoa from 0.280 to 0.257 . In a subsequent paper Ahlburg (1996) computes Gini coefficients from earlier 1984 Tongan household income and expenditure survey data. He finds that the Gini coefficients improved from 0.37 without remittances to 0.34 with remittances. If these data can be considered 
comparable (which is questionable, Ahlburg 1996: 396), they would suggest that while remittances improve distribution, over the 8-year time period, 1984-92 income distribution in Tonga had worsened. 2 This seems to be supported by the most recent estimate of the Gini coefficients at 0.42, based on the 2001 Household Income and Expenditure Survey (HIES) (ADB 2004). This suggests that despite the positive impact of remittances on income and income distribution, there is still growing inequality in Tonga. The Asian Development Bank attributes this to growing youth unemployment, combined with increasing migration from the outer islands to the main island of Tongatapu, which is increasing the dependency ratios and numbers of landless and landpoor on Tongatapu (ADB 2004).

\section{Fiji}

For Fiji there have been no previous attempts to measure the impact of remittances on income distribution. The earliest Gini coefficients for Fiji were computed for 1977 by Stavenuiter (1983) and 1990-91 by Ahlburg (1995) and reported in the government of Fiji/UNDP Fiji Poverty Report (UNDP 1996). In these studies household income is defined in terms of gross income, including cash and non-cash income as well as transfers and gifts, before tax. The Gini coefficients reported in Table 1 should therefore be interpreted as income including remittances. Using both total and per capita household income data, Ahlburg shows that income distribution deteriorated by 5 to 7 percentage points over this period, and, that this was true for both urban and rural households. However, the most recent 2002/3 estimate shows a strong improvement in distribution with the Gini coefficient of 0.34 .

Ahlburg (1995) also shows that income distribution is consistently worse for the IndoFijian community. However, Ahlburg finds evidence supporting Stavenuiter's (1983) earlier finding from the 1977 household income and expenditure survey that differences within the two main ethnic groups were much greater than the differences between them. Also of note was that poor Indo-Fijian households were considerably poorer than the poorest Indigenous-Fijians.

These estimates also indicate that income inequality in Fiji was worse than in Tonga.

Table 1

Fiji: Gini coefficients (per capita income), 1977-2002/3

\begin{tabular}{lccc}
\hline & 1977 & $1990 / 1$ & $2002 / 3$ \\
\hline National average & 0.43 & 0.49 & 0.34 \\
Indigenous-Fijian & NA & 0.42 & 0.31 \\
Indo-Fijian & NA & 0.53 & 0.36 \\
\hline
\end{tabular}

Sources: Stavenuiter (1983) for 1977; Ahlburg (1995) for 1990/1; and Abbott (2006) for 2002/3.

2 To our knowledge the only other estimate for Tonga is that of McKenzie et al. (2006), who compute a Gini coefficient of 0.338 for weekly earnings from wage, salary and self-employment, excluding remittances, which, if comparable with Brown and Connell (1993), indicates a slight improvement in income distribution over the period 1992-2006. 


\subsection{Poverty measures}

There has been only one attempt to measure the incidence of poverty in Tonga. Using 2001 household income and expenditure data, and a poverty line of T\$28.18 per capita per week, it was estimated that approximately 23 per cent of the population (i.e., the poverty headcount ratio) was in poverty in 2001 (ADB 2004). As income and expenditure would presumably include remittances and other transfers, the incidence of poverty would be substantially greater without remittances, especially in view of Tonga's very high reliance on migration and remittances, as noted previously. To date, there have been no attempts to gauge the impact of remittances on poverty in Tonga, making the results reported in this study a first (see section 5).

The earliest estimates of the incidence of poverty (poverty headcount ratio) for Fiji are based on the 1977 HIES. Stavenuiter (1983) estimates that 15 per cent of households were below the poverty line. 3 Estimates for the early 1990s vary considerably and are based on varying methods and data sources, with a range from 12 per cent to 37 per cent (see UNDP 1996: Table 12). The most reliable and widely used estimate from the 1990/1 HIES data is 25.5 per cent, based on a minimum gross household income of F\$83 per week (see Ahlburg 1995; UNDP 1996). His estimates for various regions and ethnic groups are shown in Table 2. The Poverty Task Force in Fiji estimates that the incidence of poverty had risen to between 33 and 50 per cent by 2002 (Yari 2003). The most recent official estimate is 34.4 per cent incidence (poverty headcount ratio), based on the 2002/3 HIES (Abbott 2006).

The depth of poverty, as measured by the poverty gap, is based on the average gap between the poverty line and the income of the poor, (i.e., those below the poverty line). As shown in Table 3, the gap grew from F\$666 in 1977 (poverty line $=F \$ 1,460$ per household) to $\mathrm{F} \$ 1,377$ in 1991 (poverty line = F\$4,316 per household). Although the absolute size of gap increased, the relative depth of poverty when expressed as a percentage of the poverty line fell from 46 per cent to 32 per cent between 1977 and 1991. However, the most recent estimates for 2002/3 show an increase to 44 per cent (Abbott 2006). Combining the measures of incidence and depth (i.e., the poverty headcount ratio and poverty gap) gives the poverty gap ratio, which increased from 6.8 per cent to 8.1 per cent between 1977 and 1991. By 2002/3 it had risen further, to 11.2 per cent. From these data the cost of closing the poverty gap was estimated to have risen from 1.9 per cent of GDP in 1977 to 2.4 per cent of GDP in 1991, and to 5.2 per cent of GDP in 2002/3 (UNDP 1996; Abbott 2006). These measures suggest that the incidence and depth of poverty in Fiji have worsened considerably over the last three decades. While no comparable data exist for Tonga over the same time period, the poverty gap ratio for Tonga, based on 2001 data, was estimated at 7.7 per cent (ADB 2004), suggesting that both the incidence and depth of poverty was much lower than in Fiji.

In view of the different methodologies and definitions of poverty line used, caution needs to be exercised in making comparisons between Tonga and Fiji using these data. In section 5, the incidence and depth of poverty in Fiji and Tonga based on our 2005 survey for the World Bank are calculated using a common methodology, which allows

3 Cameron (1983), using the same data but with a different poverty line, produces a lower estimate of 9 per cent. 
us to compare the impacts of migrants' remittances on both income distribution and poverty in both countries. Before presenting our findings it is necessary to discuss some important methodological issues that arise when making such comparisons using household-level survey data.

Table 2

Fiji incidence of poverty, 1977 to $2002 / 3$

\begin{tabular}{lccc}
\hline & \multicolumn{3}{c}{ Poverty headcount ratio } \\
\cline { 2 - 4 } & 1977 & $1990 / 1$ & $2002 / 3$ \\
\hline National average & 15 & 25.5 & 34.4 \\
Indigenous -Fijian & $\mathrm{NA}$ & 27.7 & 33.8 \\
Indo-Fijian & $\mathrm{NA}$ & 31.0 & 34.9 \\
Urban average & 12 & 27.6 & 31.8 \\
Indigenous -Fijian & $\mathrm{NA}$ & $\mathrm{NA}$ & 29.9 \\
Indo-Fijian & $\mathrm{NA}$ & $\mathrm{NA}$ & 33.9 \\
Rural average & 20 & 24.3 & 38.1 \\
Indigenous -Fijian & $\mathrm{NA}$ & $\mathrm{NA}$ & 37.3 \\
Indo-Fijian & $\mathrm{NA}$ & $\mathrm{NA}$ & 39.2 \\
\hline
\end{tabular}

Sources: Stavenuiter (1983) for 1977; Ahlburg (1995) for 1990/1; and Abbott (2006) for 2002/3.

Table 3

Fiji depth of poverty, 1977 to 2002/3

\begin{tabular}{lrrr}
\hline & 1977 & $1990 / 1$ & $2002 / 3$ \\
\hline Poverty line & $\mathrm{F} \$ 1,460$ & $\mathrm{~F} \$ 4,316$ & $\mathrm{~F} \$ 9,776$ \\
Poverty gap & $\mathrm{F} \$ 666$ & $\mathrm{~F} \$ 1,377$ & $\mathrm{~F} \$ 4,330$ \\
poverty gap/poverty line, \% & 46 & 32 & 44 \\
Poverty gap ratio, \% & 6.8 & 8.1 & 11.2 \\
Poverty gap/GDP, \% & 1.9 & 2.4 & 5.2
\end{tabular}

Sources: Stavenuiter (1983) for 1977; Ahlburg (1995) for 1990/1; and Abbott (2006) for 2002/3.

\section{Other country studies and methodologies}

The findings of the literature on the impact of migration and remittances on poverty and inequality indicators are rather mixed, with some studies finding positive and others negative impacts. Such contradictory findings are partly due to differences between the communities investigated, especially in relation to the types of migrant and migration histories. An improvement in inequality and poverty indicators can be expected when the poor have access to migration opportunities and remittances. This is more likely to be the case with 'mature' migrant-sending communities with high prevalence migration rates such as Tonga, Samoa and Cook Islands in the South Pacific context.4 However,

4 According to the cumulative migration theory, during the early stages of migration only households at the upper end of the income distribution can afford the migration costs and absorb its risks. The establishment of migrant's networks in the destination country reduces these migration costs and risks by providing financial and in-kind assistance to new migrants, as well as help with job hunting. 
different methodological approaches to estimating the impact of migration and remittances can also lead to different conclusions. As noted previously, the choice of methodology depends not only on the characteristics of the data being used, but also on the analyst's underlying assumptions about the relationship between migration and remittances on one hand, and poverty and inequality on the other. In the rest of this section four basic approaches identified in the current literature are discussed and the findings from studies in other countries are compared.

\subsection{Direct effects on household income and inequality 5}

The 1980s literature aimed at studying the direct impact 6 of remittances upon household income and village inequality indicators. Under the simplifying assumption that remittances are an exogenous transfer and not a substitute for migrants' home earnings, the focus of the analysis was principally on decomposition techniques and the estimation of inequality indicators, using household income including and excluding remittances. In other words, these earlier studies did not attempt to estimate the opportunity costs of migration; that is, what the migrant members would have contributed to household income had they not migrated. Neither were the indirect effects of remittances on other sources of income included in the analysis. ${ }^{7}$

One of the main contributions of this strand of the literature was to provide evidence of the different effects of remittances across communities and/or countries, depending largely at what stage they were in the migration process. The general findings were supportive of the view that income inequality worsened in the early stages of migration where only the relatively well-off households could afford the costs of migration and therefore enjoy access to supplementary remittances income. However, as migration networks expanded in the migrants' destination country, migration costs were significantly reduced, giving poorer households affordable access to migration possibilities. As the share of migrants in a population increases, the initial, negative effects of remittances on distribution weaken and could begin to have a positive effect.

In their seminal work, Stark, Taylor and Yitzhaki (1986) use Gini decomposition techniques to measure the impact of remittances on inequality in a sample of 61 households in two Mexican villages, one of which had a long history of undocumented migration to the United States, and the other, not. When comparing village Gini coefficients with and without remittances included in household income, the authors find that remittances decreased inequality in both villages, though the effect was substantially larger for the village with a long migration history.

Mature migrant-sending communities have thus lower migration costs and risks, which can be afforded by poor households (Massey, Goldring and Durand 1994).

5 The emphasis of the literature was on inequality indicators and decomposition techniques. The role of remittances in poverty alleviation did not receive special attention.

6 The direct effect is measured by the direct contribution of remittances to total household income.

7 As discussed by the new economics migration literature (NEML), migration and remittances might have indirect effects on incomes of remaining household members via the provision of insurance or the removal of liquidity constraints. A negative disincentive effect might also operate due to asymmetric information and moral hazard. 
The authors also analyse the marginal effect of remittances upon income inequality, which according to their analytical framework, depends upon three factors: (i) the share of remittances in the total village income; (ii) the inequality of remittances distribution within the village, and (iii) where the remittance recipients are located in the overall village income distribution as indicated by the correlation between remittances and total income rankings (Stark, Taylor and Yitzhaki 1986: 733). They observe that a 1 per cent increase in international remittances leads to a 0.11 per cent improvement in income distribution in the village with a long history of international migration, while worsening inequality by 0.14 per cent in the other village. A similar result is noted for the impact of internal remittances. As these authors acknowledge, these conclusions are based on the assumption that household labour and production plans do not change in response to the departure of the migrant and the inflow of remittances. However, they argue that including such indirect effects of migration upon household income would tend to strengthen rather than weaken the observed direct effects. Only in the extreme case where total household income declines in response to a marginal increase in remittances, would the observed results be altered (ibid.).

Using a similar decomposition technique, Leones and Feldman (1998) examine the impact of remittances upon inequality indicators in a representative sample of 50 households in a Philippine village with a relatively low propensity to migrate. Though only a few households (four) in the sample received international remittances, they accounted for 18 per cent of total income. This study finds remittances to be more unequally distributed than other sources of income and to play a significant role in increasing total income inequality within the village. As measured by the Gini coefficient, remittances are responsible for almost half (47 per cent) of income inequality in the village (Leones and Feldman 1998: 802).

This is essentially the same methodology as used by Ahlburg (1991, 1995, 1996), Brown and Connell (1993) and others in their estimates of the impact of remittances on inequality in the South Pacific as discussed in section 2 of this paper.

\subsection{Indirect effects on household income and inequality}

A distinguishing feature of the new economics of labour migration (NELM) pioneered by Stark and Levhari (1982) has been the inclusion of potential indirect effects of migration and remittances on other sources of income in the migrant-sending household. Taylor (1992) breaks new ground by using a simultaneous equations approach to estimate these indirect effects and to incorporate them in the analysis of inequality with and without remittances.

According to the NELM, the migration decision and the subsequent remittance inflows affect the household's exposure to income risks, as well as its investment and production decisions. Migrant remittances might provide insurance and relieve the household's budget constraint which in turn might lead the remaining household members to adopt riskier or costly production techniques with higher potential returns. On the downside, remittances might also increase the reservation wage of remaining household members, thus affecting their labour participation and supply decisions. As a result, when the indirect effects of insurance, investment and liquidity prevail, the marginal impact of remittances on total household income is hypothesized greater than unity. In contrast when the disincentive effect prevails, the marginal impact will be less 
than unity (Taylor 1992). Intertemporal, long-run effects of remittances might also be at play if households decide to invest their remittances in productive assets, which then provide an additional contribution to household's total income in subsequent years.

Two studies of a longitudinal sample of 55 rural households in Mexico carried out by Taylor (1992) and Taylor and Wyatt (1996) incorporate these indirect and intertemporal effects into the analysis of the impact of remittance on inequality indicators. In a first scenario where only the direct effects of remittances are taken into account, Taylor (1992) finds remittances to be less equally distributed than farm income. However, since recipient households were located at the lower end of the village income distribution, the Gini coefficient improved, or at least did not worsen, when remittances were included in the calculations for the two time-periods under study. The marginal effects of remittances on income distribution were found to be positive, although they weakened over time from 0.03 per cent in 1982 and 0.01 per cent in 1988, as migration opportunities became accessible to relatively poor households.

The author also analyses an alternative scenario, where the indirect effects of remittances on other sources of income were incorporated (Taylor 1992). First, these effects are noted to be negative in the earlier year, 1982, but then to become positive in 1988. As a result, the indirect effects of remittances reinforced the negative marginal impact of remittances in 1988, while partially offset their negative effects in 1982. However, once the longer-term investment effects of remittances were included, a marginal increase in the amount of remittances in 1982 resulted in an improvement in the 1988 Gini coefficient (-0.01 per cent).

Taylor's analytical framework is extended in Taylor and Wyatt (1996), who use similar techniques to analyze the same dataset for 1988, but relaxing the assumption of constant indirect effects (shadow value) of remittances across all households. They argue that remittances will have weaker indirect effects on wealthy households who do not face liquidity constraints and are able to absorb their production risks, without relying on migrants' remittances. The authors find that the marginal income effects of remittances varied widely across the household asset distribution. The larger the value of a household's assets, the larger the positive marginal effects of remittances on income. The direct marginal effect of remittances reduced inequality but by very little $(-0.07$ per cent), but once the indirect effects were taken into account, the impact of remittances on inequality became stronger ( -0.26 per cent), which is explained by the larger shadow value (indirect effects) of remittances for households at the middle-to-bottom end of the income distribution.

This strand of the literature therefore extends the Gini decomposition analysis introduced by Stark, Taylor and Yitzhaki (1986), by using econometric techniques to estimate the indirect effects of remittances on earnings of the remaining household members, which are then incorporated into the inequality analysis. However, by focusing on the impact of remittances on the income of remaining household members, this analytical framework still excludes the opportunity costs of migration; that is, what the migrants would be contributing to household income had they decided to stay. 8

8 See, for example, Taylor, Rozelle and de Brauw (2003: 91). 
As a consequence, the more recent focus of the migration and remittances literature has been on the development of a methodology to estimate a counterfactual income for households with migrants and remittances. This would allow the analyst to estimate what the household's level of welfare would have been, as measured by income or consumption, in the absence of migration. This counterfactual welfare level is then used to estimate what the poverty and inequality indicators would have been in a hypothetical scenario of no-migration, which are then compared with actual income including remittances. Studies following this approach are discussed later in this section (3.4) of the paper.

\subsection{Net effects on poverty and inequality indicators after controlling for endogeneity}

It is also worth noting that a different strand of the recent literature has addressed the impact of migration and remittances on inequality and poverty indicators at the community level. The focus here is on measuring the net effects of migration on community-level indicators of poverty and inequality. Taking advantage of large datasets, which allow analysis at the community rather than household level, recent studies have estimated national or community indicators of poverty and inequality as a function of migration prevalence rates. Instrumental variable techniques are then used to control for potential endogeneity bias ${ }^{9}$ that might arise due to several factors such as self-selection of migrants, reverse causation or omitted variables. 10

Adams and Page (2005) study the impact of international migration and remittances on poverty indicators in 71 low-income and middle-income developing countries. After controlling for endogeneity, the study finds both variables to have a strong impact on poverty reduction. A 10 per cent increase in the proportion of international migrants in a country's population leads to a 2.1 per cent fall in the number of people living on less than US\$ 1 a day.

Similar conclusions are also drawn by Lopez-Cordoba (2004). He analyses the impact of remittances on poverty indicators, using a cross-section of 2,443 Mexican municipalities. He notes that after controlling for endogeneity, a 1 per cent increase in the proportion of remittance-receiving households in a community is associated with a 4.5 per cent decline in the proportion of the population earning less than the minimum wage.

9 Under endogeneity, the OLS coefficients will be biased. They will reflect both the net impact of the explanatory variable as well as the endogeneity bias. Formally:

$p \lim \left(\hat{\beta}_{1}\right)=\beta_{1}+\frac{\operatorname{Cov}(X, v)}{\operatorname{Var}(X)}$.

10 Several examples can illustrate the potential endogeneity bias in migration and remittances studies, as follows: (i) Self-selection: Should migrants be positively (negatively) selected in regard to education, they will tend to come from the upper (lower) end of the income distribution. (ii) Reverse causation: The relationship between poverty and remittances might be bi-directional. The poorer a community is, the more incentives people would have to migrate and remit. On the other hand, remittances received by poor household will have a negative effect on poverty indicators. (iii) Omitted variable: Community levels of social capital might not be observable. However, they might have an impact on both the dependent variable (poverty indicators) and the independent variable (migration levels). 
In relation to inequality, McKenzie (2006) studies Mexican data, using a sample of 214 municipalities with a population less than 100,000. As suggested by the migration literature, he notes that during the early stages of migration, inequality in a community increases, but this effect is reversed as migration opportunities become available to a wider section of the population. The impact of migration is rather large with a one-standard deviation increase in migration prevalence being associated with a 0.5 standard deviation improvement in the Gini coefficient.

Yang and Martinez (2006) examine the effects of remittances upon poverty and inequality indicators in the Philippines. The authors use a set of linked household surveys and a sample of 26,121 households. They 'exploit a unique natural experiment', the major exchange rate shocks during the Asian crises, that provides them with an instrument that isolates the net impact of remittance flows on the outcome variables. This study finds that a 3 per cent improvement in the region-level migrant exchange rate (their instrument for remittances) leads to a 1.8 percentage point decline in the regional poverty rate. However the effect on the poverty gap and inequality indicators was not statistically significant.

What these studies have in common, therefore, is their focus on the specific econometric question of estimating the net effects of migration on regional inequality and poverty indicators. In their analyses they use a cross-section of countries (Adams and Page 2005), regions (Yang and Martinez 2006) or local communities (Lopez-Cordoba 2004; McKenzie 2006). In contrast, when the object of the analysis is to examine the impact of migration on poverty and inequality indicators in a single community, or, as in our case, small island economies, the econometric question to be addressed is what the poverty and inequality indicators would be in a counterfactual scenario of no-migration.

\subsection{Building a counterfactual 'no-migration' scenario}

The studies reviewed in this subsection use a cross-section of households within a country (Adams 1989 and 2006; Rodriguez 1998) or a local community (Barham and Boucher 1998). In this approach the focus is on determining whether poverty and inequality levels are lower in the actual scenario, with migration and remittances, than in a hypothetical counterfactual scenario without migration and remittances. The core of the methodology consists of estimating what the migrant household's income would be if migrant members had decided to stay, that is, a 'counterfactual household income'. The estimated counterfactual household income needs to remove both the direct 11 and indirect 12 effects of migration on the earnings of remaining household members, while imputing the home earnings of migrants had they not migrated. However, it should be noted that this methodology implicitly assumes that the labour market conditions are unaffected by the outflow of migrants and subsequent inflow of remittances. In other words, the labour market conditions that prevail in the with-migration scenario are assumed to be the same for the counterfactual without-migration scenario.

11 The direct effects of migration on household income as measured by the amount of remittances received.

12 As previously discussed, indirect or spillover effects might arise due to insurance provision, loosening of liquidity constraints and increasing the reservation wage of remaining household members. 
The 'counterfactual approach' was initially developed by Adams (1989) in his study of the effects of remittances on poverty and inequality in a sample of 1,000 households across three villages in Egypt. In order to estimate the counterfactual household income, he estimates a mean regression of incomes of non-migrant households and uses the resulting parameters to predict the incomes of migrant households. These predicted incomes of migrant households were then used to estimate poverty and inequality in a counterfactual scenario of no-migration. While inequality as measured by the Gini coefficient is noted to worsen from 0.23 to 0.29 when remittances were included, the poverty headcount ratio decreased from 26.8 per cent to 24.4 per cent.

A similar methodology is used by Rodriguez (1998) to study the impact of migration13 on inequality, using a sample of 24,782 households in the Philippines. When remittances are treated as an exogenous transfer to the household, inequality as measured by the Gini coefficient, deteriorated by 1.3 per cent. When a counterfactual methodology is used and remittances treated as a substitute for migrants' home earnings, the negative impact of migration on income distribution is significantly stronger with the Gini coefficient increasing by 7.9 per cent.

Nevertheless, it should be pointed out that estimated counterfactual income in both of these studies might lead to biased estimates due to potential self-selection bias. If observed household migrants are not a random draw of the population, using the regression parameters of non-migrant households will bias the counterfactual income estimates.

Barham and Boucher's (1998) study on Nicaragua and Adams' (2006) analysis of Guatemala test for self-selection of migrant households and in both instances conclude that migrant households do not appear to be self-selected. Any bias resulting from the ordinary least squares estimates without selection controls would therefore be small. They then estimate counterfactual incomes to compare poverty and inequality indicators with and without migration. Barham and Boucher conclude that when remittances are treated as an exogenous transfer, inequality as measured by the Gini coefficient declines by 9 per cent. However when remittances are treated as a substitute for individual migrant's income and their indirect effects are taken into account, inequality increases. Adams finds that when both internal and international remittances are included, the poverty headcount ratio decreases by 2.01 per cent, while the poverty gap declines by 3.64 per cent. Their impact on the Gini coefficient is also negative, though small $(-0.20$ per cent).

It is therefore clear that the conclusions drawn from studies of the impact of migration and remittances on income inequality and poverty are varied, and, very often their conflicting findings are a function of the assumptions and methodology followed when estimating the counterfactual, without-remittances income of the migrant-sending household. What is of particular importance is that when migrants' remittances are not treated as an exogenous addition to income, and their forgone earnings are imputed into household income in the non-migration scenario, results and conclusions can be reversed.

13 The author also uses the Gini decomposition analysis as described in subsection 3.1. The results are similar to those obtained with the counterfactual methodology. 


\subsection{The methodology of this study}

The purpose of this study is to analyse the impact of migration on inequality and poverty levels in Fiji and Tonga using our 2005 dataset compiled for the World Bank study (Brown et al. 2006). Taking into account the characteristics of the dataset, this study follows a basic counterfactual approach as discussed in the previous subsection. This approach assumes migrants to be a non-random group of the population and sets the stochastic term to zero. 14

Before discussing in detail the econometric model, several issues deserve some consideration. First, migration decisions as well as other decisions regarding the allocation of household labour to economic activities are assumed to be made at the household level.15 Thus, following the NELM, the unit of analysis is the household, rather than individual household members. Second, as discussed later, in both countries households without migrants also receive remittances (see Table 5). It is assumed here that remittances received by non-migrant households 16 are exogenous additions to household income. The reason for imputing the forgone earnings of migrants is that they represent the opportunity cost of migration to the household to which the migrant belonged. It seems reasonable then to assume that households that receive remittances but do not send any migrants abroad have not had to forgo any income, and so, for them, remittances are an exogenous transfer. (In the no-migration scenario, household income for both migrant and non-migrant households excludes all remittances, irrespective of whether they are sent by household members or others.) Third, in order to improve the appropriateness of the counterfactual imputations, the natural log of household income, rather than total income, is used as the dependent variable in the regression analysis.

In order to construct what household income would be in the no-migration scenario, this study aims at estimating a mean regression of natural log incomes of non-migrant households. Under the assumption of no self-selection, the resulting parameters are used to predict the expected natural log income of migrant households. The predicted values of the natural log of income for migrant households thus estimated are then used to calculate per capita household income adjusted by adult equivalent scales. It is assumed that a child under 14 is equivalent to 0.5 adults. 17 Following Deaton (1997: ch. 3), poverty and inequality indicators are calculated using household data weighted by household size.

14 It should be noted that when the predicted income of migrant households is based only on the estimated parameter coefficients, with the stochastic term set to zero, it is possible that variance in household income is artificially reduced which could influence the results (Adams 1989; Barham and Boucher 1998; Rodriguez 1998). The use of a counterfactual methodology testing for self-selection and using stochastic imputation is work in progress as part of Eliana Jimenez's ongoing PhD thesis.

15 Note that the definitions used in the survey for household 'those who cook and eat from the same pot', as well as for migrant household members 'those who lived with the household before migrating or would live with the household if they were to return', include both nuclear and extended family.

16 According to the definition of migrant household members, non-migrant households receive remittances from friends and relatives who neither lived with the household before migrating nor would live with them if returning.

17 Narsey (2006) uses this adult-equivalent scale in his study of urban poverty in Fiji, following a common practice in international studies 


\section{The data}

\subsection{The survey}

The survey was prepared and conducted in the first half of 2005. (For details of the design of the survey instrument, selection of enumeration areas, sampling and survey administration, see Appendix C of Brown et al. 2006.) The overall sample of 918 households was made up of 418 households in Fiji and 500 in Tonga and as previously discussed, information was collected for the household and for each individual within the household, giving a total of 4,663 sampled individuals, 1,937 in Fiji and 2,726 in Tonga.

\subsection{The Fiji sample}

Fiji, with a population of 836,000, comprises 322 islands, with approximately 110 of them inhabited, though the largest two islands, Viti-Levu and Vanua Levu, are home to over 94 per cent of the people. The main population centres, including the capital, Suva, are located in the main island, Viti-Levu, which accounts for over 70 per cent of the residents. However, due to budget constraints, the survey sample was drawn from VitiLevu only, excluding Vanua Levu and the outer islands.

The survey sample consisted of urban and rural enumeration areas, scattered across Viti-Levu. They cover the capital city, Suva; the five major towns in both provinces (Nausori, Lautoka, Nadi, Ba and Sigatoka); nine villages and twelve settlements. In total 420 households were interviewed, with only two refusing to answer the questionnaire, which left 418 households in our sample.

\subsection{The Tongan sample}

The Kingdom of Tonga embraces 171 islands, of which around 40 are populated. Out of the 100,000 Tongan residents, only 25 per cent live in the outer islands, with the large majority of the population living in the main island of Tongatapu and mostly concentrated in the capital, Nuku'alofa. The capital city is home to around 50 per cent of the people.

This population split is reflected in the survey sample, which was selected directly by the Department of Statistics in Nuku'alofa. The primary sampling units consist of 20 enumeration areas covering both the urban and rural population. In total, the Tongan sample consists of 500 households drawn from the capital city Nuku'alofa, four districts of rural Tongatapu and the remaining 125 households chosen from two groups of outer islands, Vava'u and Hapa'i.

\subsection{Sample characteristics}

As can be seen in Table 4, the survey sample reflects the almost even urban-rural split of the population in Tonga and the main island of Fiji, Viti Levu, as well as the ethnic distribution in the latter, with 50.5 per cent of the Fiji sample being Indo-Fijian, 47.1 per cent Indigenous-Fijian (abbreviated to Indig-Fijian in Table 4) and the remaining 2.4 per cent constituting other ethnic groups. 
Table 5 shows which households had received remittances in one form or another over the preceding year.18 The sample is split between those households with at least one migrant and those without any migrant members. As expected, most households with a migrant member received remittances: 86.8 per cent in Fiji and 97.6 per cent in Tonga. Although the high incidence of remitting migrants was to be expected from previous knowledge about remittances and migration networks in the region, what was not expected was the high proportion of households without any migrants who were also in receipt of remittances.

In Tonga, where migration- and remittances-dependency have been long established and have become almost ubiquitous, nearly 80 per cent of non-migrant households had received remittances in 2004. In Fiji, the less 'mature' migration-and-remittances economy, almost 20 per cent of households without migrants had received remittances. Of the total sample, 90.9 per cent of Tongan and 42.0 per cent of Fiji households received remittances. 19

Within the two main ethnic groups in Fiji a similar proportion of migrant households received remittances: 84.7 per cent among Indo-Fijians and 89.1 per cent among Indigenous-Fijians. However, a somewhat larger proportion of Indo-Fijian households without a migrant received remittances (26.8 per cent), in comparison with IndigenousFijian households (14.7 per cent).

These observations are important for they suggest that as migration and remittances become more commonplace in an economy, non-migrant households can benefit more from direct access to remittances. This points to a more nuanced view on the relationship between migration, remittances and household living standards and inequality in these societies than what is generally argued in most other studies of migration and remittances where it is normally assumed that it is only the immediate family members of the migrant who stand to benefit, at least directly, from the flows of remittances.

Finally, in Table 6, summary statistics show the extent of mean income differences between households with and without migrants. 20

In both countries, both household income and income per capita are higher for households with migrants. However, it is also noticeable that for Tongan households the variability of income is considerably higher for migrant households, whereas for Fiji households this is the case for non-migrant households.

18 In this study remittances are defined broadly to include cash transferred both formally through the financial system and informally, hand-carried, as well as remittances in kind (e.g., goods sent or carried by the migrant), as well as payments such as airfares, made by the migrant on behalf of the recipient household.

19 The percentage for Tonga is considerably higher than the 75 per cent found in the 2001 HIES. The most likely explanation for the difference is that the HIES used a rather general question about cash remittances only, while this questionnaire asks numerous questions with cross-checks to assist the respondent in recalling transfers that might not have been considered remittances, such as in-kind transfers, and bills paid on behalf of the household. The 91 per cent figure is also very similar to what was observed in a similar survey over a decade earlier (Brown 1995).

20 Income includes estimates of subsistence income derived from the survey data. 
Table 4

Composition of 2005 household sample, Fiji and Tonga

\begin{tabular}{llccl}
\hline Country & & Urban & Rural & Total \\
\hline Fiji & $\mathrm{n}=$ & 208 & 210 & 418 \\
& $\%$ & 49.76 & 50.24 & 100.00 \\
Tonga & $\mathrm{n}=$ & 250 & 250 & 500 \\
& $\%$ & 50.00 & 50.00 & 100.00 \\
Total & $\mathrm{n}=$ & 458 & 460 & 918 \\
& $\%$ & 49.89 & 50.11 & 100.00 \\
& & & Fiji by ethnic group & \\
Indo-Fijian & $\mathrm{n}=$ & 90 & 197 \\
& $\%$ & 107 & 45.69 & 100.00 \\
Indig-Fijian & $\mathrm{n}=$ & 54.31 & 117 & 211 \\
& $\%$ & 94 & 55.45 & 100.00 \\
\hline
\end{tabular}

Source: Brown et al. (2006).

Table 5

Households receiving remittances, Fiji and Tonga, 2004

\begin{tabular}{|c|c|c|c|c|c|c|}
\hline \multirow{3}{*}{ Migrants in $\mathrm{HH}$ ? } & \multicolumn{3}{|c|}{ Fiji } & \multicolumn{3}{|c|}{ Tonga } \\
\hline & \multicolumn{3}{|c|}{ Received remittances? } & \multicolumn{3}{|c|}{ Received remittances? } \\
\hline & No & Yes & Total & No & Yes & Total \\
\hline No & 220 & 54 & 274 & 45 & 164 & 209 \\
\hline$(\%)$ & 80.29 & 19.71 & 65.55 & 21.53 & 78.47 & 41.80 \\
\hline Yes & 19 & 125 & 144 & 7 & 284 & 291 \\
\hline$(\%)$ & 13.19 & 86.81 & 34.45 & 2.41 & 97.59 & 58.20 \\
\hline Total & 239 & 179 & 418 & 52 & 448 & 500 \\
\hline$(\%)$ & 57.18 & 42.82 & 100 & 10.40 & 89.60 & 100 \\
\hline
\end{tabular}

Source: Brown et al. (2006).

Table 6

Summary statistics for household income, with and without migrants

\begin{tabular}{|c|c|c|c|c|}
\hline & \multicolumn{2}{|c|}{ Fiji } & \multicolumn{2}{|c|}{ Tonga } \\
\hline & Mean & Std dev. & Mean & Std dev. \\
\hline & \multicolumn{4}{|c|}{ Households with migrants } \\
\hline $\mathrm{HH}$ income & $7,248.65$ & $6,565.97$ & $6,643.31$ & $12,839.66$ \\
\hline Income/capita & $1,869.75$ & $1,793.38$ & $1,757.96$ & $4,869.00$ \\
\hline \multirow[t]{2}{*}{ Income/capita adult equiv } & $2,040.29$ & $1,967.53$ & $1,910.28$ & $4,926.78$ \\
\hline & \multicolumn{4}{|c|}{ Households without migrants } \\
\hline $\mathrm{HH}$ income & $6,364.67$ & $9,506.45$ & $4,718.59$ & $4,512.47$ \\
\hline Income/capita & $1,580.89$ & $2,289.70$ & 946.63 & 789.97 \\
\hline Income/capita adult equiv & $1,732.042$ & $2,370.044$ & $1,138.95$ & 972.61 \\
\hline
\end{tabular}

Source: Brown et al. (2006).

\section{$4 \quad$ Results}

Table 7 shows the definitions and summary statistics of the variables used to estimate the natural log of income regressions. 
Table 7

Definitions and descriptive statistics for variables in regressions

\begin{tabular}{|c|c|c|c|c|}
\hline \multirow[b]{2}{*}{ Variable description } & \multicolumn{2}{|c|}{ Fiji } & \multicolumn{2}{|c|}{ Tonga } \\
\hline & Mean & Std dev. & Mean & Std dev. \\
\hline Dummy non-migrant household & 0.65 & & 0.42 & \\
\hline Household size including migrants & 5.37 & 2.48 & 6.85 & 3.27 \\
\hline Ratio of $\mathrm{HH}$ Members under 14 and over 60 , incl. migrants & 0.24 & 0.22 & 0.32 & 0.23 \\
\hline Dummy $\mathrm{HH}$ with female head & 0.18 & & 0.22 & \\
\hline $\mathrm{HH}$ head age & 46.46 & 13.12 & 51.89 & 14.90 \\
\hline $\mathrm{HH}$ head age square & 2330.1 & 1327.15 & 2914.51 & 1607.96 \\
\hline Dummy $\mathrm{HH}$ lives in urban area & 0.495 & & 0.50 & \\
\hline Dummy Indo-Fijian household & 0.47 & & na & \\
\hline Dummy for outer island $\mathrm{HH}$ & na & & 0.25 & \\
\hline Average years of education of adult $\mathrm{HHM}$, incl. migrants* & 10.25 & 2.85 & 0.48 & \\
\hline Dummy for female-headed $\mathrm{HH}$ with a tertiary educated member & na & & 0.07 & \\
\hline $\begin{array}{l}\text { Interaction dummy Indo-Fijian and average yrs of education } \\
\text { of adults }\end{array}$ & 4.85 & 5.55 & & \\
\hline Dummy HH owns agricultural land in 2003 & 0.22 & 0.41 & 0.51 & 0.50 \\
\hline
\end{tabular}

Note: $\quad{ }^{*}$ For Tonga this is dummy variable for presence of $\mathrm{HH}$ member with tertiary education.

\subsection{Poverty and inequality indicators in the actual and counterfactual scenarios}

Following the imputation methodology discussed in section 3, the results of the natural log of income regressions for the subsample of non-migrant households were used to estimate income for migrant households. 21 This imputed income, which sets remittances to zero, is then used to calculate per capita household income adjusted by adultequivalent scales. This estimation incorporates all household members including migrants and non-migrants and assumes that one child under 14 is equivalent to 0.5 of an adult. 22

For comparability purposes, the Gini coefficient is used as a measure of inequality, while the poverty analysis uses the poverty headcount ratio and the poverty gap indicators discussed in section 2. Due to unavailability of official data to estimate per capita poverty lines and the questionnaire design, this study uses a subjective poverty line, constructed from the survey data. 23 The questionnaire included a minimum cash income question, which asked respondents how much money a family like theirs

21 These regressions assume that remittances received by non-migrant households have no indirect effects in their income. See Appendix for detailed results.

22 Similar results were also obtained when poverty and inequality indicators were calculated using per capita household income, without adjusting for adult-equivalent scales.

23 The survey collected information about annual income and not household consumption. In order to minimize the recollection bias, households were first asked about the minimum income required to get by. This was followed by another question regarding whether they thought the survey year was good or bad in terms of income; that is, whether their income was sufficient to get by, taking into account their previous answer. After this, the question about actual sources of income during the preceding year (2004) was put to the respondents. Importantly, responses to their actual income questions were in reference to their subjective 'required income' responses. 
required 'just to get by'. Household subsistence income, also derived from the survey, was added to this amount to estimate the total income that each household considered the minimum to get by. Once the total required income had been estimated for each household, this amount was divided by the adult-equivalent number of household members, where each child was counted as equivalent to 0.5 adults. Following the procedure used commonly in the poverty literature, the poverty line was then estimated as the median of the required per capita adult-equivalent income in the sample. A poverty line of US\$765 in Fiji and US\$879 in Tonga were thus derived.24

Table 8 presents the results for the analysis of poverty and inequality indicators, which were estimated using the household-level data weighted by household size. The table shows the estimated poverty and inequality indicators under each scenario, as well as their percentage change when compared against the indicators obtained using actual household income, including remittances. To calculate the Gini coefficient, a bootstrap procedure was used to derive confidence intervals for the Gini coefficients (95 per cent confidence intervals) across the different scenarios. These bias-corrected confidence intervals are reported in the rows below the Gini coefficients in Table 8.

Three basic scenarios are reported. In the first scenario-observed income without remittance-the indicators are estimated using observed income (inclusive of subsistence income) excluding remittances for all households, with and without migrants. This scenario treats remittances as an exogenous addition to income from other sources, and only domestically-resident household members are included in the calculation of per capita income, as in all previous studies of remittances and income inequality in the South Pacific as discussed in section 2.

Table 8

Poverty and income inequality indicators with and without remittances

\begin{tabular}{|c|c|c|c|}
\hline & \multicolumn{2}{|c|}{ Without migration counterfactual } & \multirow{3}{*}{$\begin{array}{c}\text { With migration actual } \\
\text { Observed income } \\
\text { including remittances }\end{array}$} \\
\hline & Method 1 & Method 2 & \\
\hline & $\begin{array}{l}\text { Observed income } \\
\text { without remittances }\end{array}$ & $\begin{array}{l}\text { Counterfactual income } \\
\text { without remittances }\end{array}$ & \\
\hline & \multicolumn{2}{|c|}{ Poverty headcount ratio, \% } & \\
\hline Fiji $(\mathrm{a}$ & 38.4 & 42.9 & 34.1 \\
\hline \multirow[t]{2}{*}{ Tonga ${ }^{(a}$} & 54.7 & 62.1 & 32.4 \\
\hline & \multicolumn{2}{|c|}{ Poverty gap ratio, \% } & \\
\hline Fiji & 18.2 & 17.3 & 15.1 \\
\hline \multirow[t]{2}{*}{ Tonga } & 27.5 & 27.1 & 11.6 \\
\hline & \multicolumn{2}{|l|}{ Gini coefficient } & \\
\hline Fiji & 0.51 & 0.47 & 0.50 \\
\hline Bias corrected $(\mathrm{b}$ & $0.47-0.54$ & $0.43-0.52$ & $0.47-0.54$ \\
\hline Tonga & 0.53 & 0.42 & 0.46 \\
\hline Bias corrected ${ }^{(b}$ & $0.47-0.59$ & $0.39-0.47$ & $0.42-0.51$ \\
\hline
\end{tabular}

Notes: (a Estimated poverty line for Fiji = US\$765 and US\$879 in Tonga per adult per annum; (b At 95 per cent confidence interval.

24 These convert to approximately F\$1,362 and T\$1,749 respectively at the nominal exchange rate. 
The second scenario_-counterfactual income-assumes remittances are a substitute for migrants' home earnings and uses the basic counterfactual methodology previously discussed to estimate what the poverty and inequality indicators would be without migration. Indicators are calculated using observed income for non-migrant households (excluding remittances from non-household members), and the counterfactual income for migrant households, excluding all remittances. Both domestically-resident and migrant household members are included in calculating per capita income. 25

Finally, the third scenario-observed income with remittances-presents the actual scenario with migration, under which the poverty and inequality indicators are calculated using observed income including remittances received by all households. Only domestically-resident household members are included in the calculation of per capita income. 26

Comparing these with the previous estimates of poverty and income distribution in the South Pacific as discussed in section 2 shows some interesting similarities and differences. For Fiji the poverty headcount ratio including remittances of 34.1 per cent is remarkably close to Abbott's (2006) estimate of 34.4 per cent based on 2002/3 HIES data, despite the different methodology for deriving a poverty line. On the other hand, our estimate for Tonga of 32.4 per cent is considerably higher than the only previous estimate of 23 per cent for 2001 (ADB 2004). Nevertheless, our results are consistent with the previous studies in showing that the incidence of poverty is worse in Fiji than in Tonga, albeit only slightly.

For income distribution we find that our estimated Gini coefficient for Tonga (0.46) is quite close to the 2001 estimate of 0.42 by ADB (2004). For Fiji, however, our estimated Gini coefficient of 0.50 is considerably higher than the most recent 2002/3 estimate of 0.34 (Abbott 2006). Thus, contrary to the previous estimates for these two countries, our results indicate that income distribution is also worse in Fiji than in Tonga.

As Tonga is much more dependent on migration and remittances, these findings provide indirect support for the hypothesis that migration and remittances have a positive impact on income distribution and poverty. We test this more directly by comparing the various ratios with and without migration and remittances.

As can be seen in Table 8, the poverty headcount and the poverty gap ratios in both countries are substantially lower in the observed with migration and remittances scenario than in either of the counterfactual without scenarios. These results provide strong evidence that migration and the subsequent inflow of remittances alleviate poverty in Fiji and Tonga. When remittances are treated as an exogenous addition to income, the poverty headcount ratio decreases by 11 per cent in Fiji and 41 per cent in

25 For this reason it is conceivable that per capita income with imputed migrants' earnings (second scenario) is less than per capita income without imputed migrants' earnings (first scenario) as the denominator is larger when migrants are added to domestically-resident household members.

26 Excluding migrants' income from the estimates of per capita household income is tantamount to assuming that the income and consumption of the migrant members are not relevant from a household welfare perspective, or that the migrant is at least no worse-off than other household members. While this assumption is questionable, in the absence of information on migrants' earnings and consumption abroad no alternative is possible. 
Tonga. That is, the percentage of poor households declines from 38 per cent to 34 per cent in Fiji, and from 45 per cent to 32 per cent in Tonga. The poverty gap ratio also declines in both countries. In Fiji this ratio is reduced by 17 per cent, and by 58 per cent in Tonga. These results confirm that the choice of methodology for computing the without migration and remittances scenario has a significant impact on the results and conclusions drawn.

The results also show that the poverty alleviation impact of remittances is substantially underestimated when the methodology, simplistically, treats remittances as an exogenous addition to income. The estimated improvement in the poverty indicators with remittances is substantially larger when we use the more complex methodology in which remittances are assumed to be endogenous in the hypothetical, no-migration scenario. Using this methodology, the incidence of poor households declines from 43 per cent to 34 per cent in Fiji and from 62 per cent to 32 per cent in Tonga. In other words, the poverty headcount ratio improves by 21 per cent in Fiji and by 47 per cent in Tonga. Similarly, the poverty gap ratio is reduced by 13 per cent in Fiji and by 57 per cent in Tonga. This finding might be explained by different factors.

First, as discussed in section 3, migration of household members might have an indirect positive impact on the income of the remaining household members, via insurance or liquidity-constraint effects, which are not captured when remittances are treated as exogenous additions to household income. Second, in settings with labour surplus, such as appears to be the case in Fiji and Tonga, the marginal contribution of the migrant's home earnings to per capita household income might be negative. In other words, if the migrant's marginal contribution to household income was less than the household's per capita income, leaving the household raises the per capita income of those remaining. By the same reasoning, when under the no-migration hypothetical scenario the number of resident household members increases, per capita household income will fall if the migrant's imputed earnings are lower than the mean of all other household members.

On the other hand, the extent to which migration and remittances alleviate poverty appears to depend also on the country's migration history. Comparing the changes in poverty indicators in a country with a longer tradition of out-migration, such as Tonga, indicates an important difference. Both methodologies show a higher incidence of poverty in Tonga (55 per cent and 62 per cent) than in Fiji (38 per cent and 43 per cent) before taking account of the effects of migration and remittances. Once the effects of migration and remittances are included, the poverty alleviating impact is substantially greater, with the end result that the incidence of poverty is lower in Tonga (32.4 per cent) than in Fiji (34.1 per cent). Similarly results are shown for the poverty gap ratio measuring the depth of poverty. Without migration and remittances the depth of poverty is higher in Tonga than in Fiji, but once their impacts are included the poverty gap ratio falls in both countries, but by so much more in Tonga that the end result is that the poverty gap ratio (11.6 per cent) for Tonga is significantly lower than Fiji's (15.1 per cent).

Regarding the impact of migration and remittances on measures of inequality, the findings are rather ambiguous. In Fiji, when remittances are treated as exogenous additions to income, there is only a slight improvement in the Gini coefficient; it falls from 0.51 to 0.50 , representing a 2.15 per cent improvement. Moreover, this apparent improvement is not unambiguous as there is a substantial overlap in the confidence intervals $(0.47-0.54$ versus $0.46-0.54)$. When the Gini coefficient is estimated using the 
counterfactual income approach again an ambiguous change is observed but in this instance there is an increase in inequality. The Gini coefficient increases from 0.47 to 0.50 , representing a 10 per cent increase in inequality, but as there is a substantial overlap in the confidence intervals (0.43-0.52 versus $0.47-0.52)$ this result is not unambiguous.

In Tonga, on the other hand, when remittances are treated as exogenous additions to income, a substantial decline in inequality is observed. The Gini coefficient is reduced from 0.53 to 0.46 , implying an improvement of 13 per cent. However, when the hypothetical counterfactual estimation method is used, the confidence intervals of the two Gini coefficients overlap, indicating that migration and remittances do not cause an unambiguous improvement in income distribution. In neither case therefore does it appear that migration and remittances have an unambiguous positive effect on income distribution.

These apparently contradictory findings, where migration appears to reduce poverty substantially, but has little or no impact on inequality could be explained by the findings from other analysis of these data on migrants' motivations to remit.27 Remittances were found to be motivated by altruism implying that the poorer the household is, the higher the level of remittances it receives. This would explain the important poverty alleviation role of remittances found in this study. On the other hand, it is also noted that remittances to the wealthier households were motivated by 'exchange' (or 'selfinterest'), implying that the wealthier the household, the higher the amount of remittances it received. If the propensity to remit to high-income households is equally as strong as it is for poorer households, then it is to be expected that remittances, while alleviating poverty at the lower end of the income spectrum, will tend also to reinforce existing income inequalities.

\section{Conclusions}

This paper addresses the question of how migration and remittances impact on poverty and income distribution in two small Pacific island economies, Fiji and Tonga. We use household-level survey data from both countries to estimate a without migration and remittances counterfactual household income scenario, against which to compare actual, with migration and remittances income.

Our results are interesting in a number of respects. First, they show that the choice of methodology can have a significant impact on the estimated impacts and conclusions made about the impacts of migration and remittances on income distribution and poverty. We compare the estimated impacts using the counterfactual approach discussed above, with the more simplistic and more commonly used method which treats remittances as an exogenous addition to other sources of household income. We find that in both countries, the impact on poverty measures is considerably greater when the methodologically superior counterfactual estimation method is used.

27 This work is in progress as part of Eliana Jimenez’s ongoing PhD thesis. Results available on request. 
Second, in relation to income distribution we find that after using the counterfactual methodology, the impact on distribution is much weaker than previously estimated, and the results are rather ambiguous. Nevertheless we find that the Gini coefficients with remittances included leave Tonga with a more egalitarian distribution than Fiji. This is most probably attributable to the much longer time period over which Fiji has experienced the positive distributional impacts of migration and remittances.

Third, we find that the impact of migration and remittances on poverty alleviation is so much stronger in Tonga than in Fiji that although Tonga has a higher incidence and depth of poverty than Fiji in the counterfactual without migration and remittances scenario, Tonga, with migration and remittances, enjoys a considerably lower incidence and depth of poverty than Fiji. We attribute this to Tonga's longer history and more widespread incidence of remittance-receiving households.

There is, therefore, both indirect and direct evidence that migration and remittances have a strong, positive effect on the alleviation of poverty and distribution of income in both countries. 


\section{Appendix 1: Regression results}

Table A1

Regression results for non-migrant household income, Fiji

$($ Dependent variable $=$ natural log of income $)$

\begin{tabular}{lcc} 
Number of obs & \multicolumn{2}{c}{268} \\
F(11, 256) & 0.0000 & \\
Prob $>$ F & 0.2994 & \\
R-squared & 0.2721 & \\
Adj R2 & 0.89651 & \\
Root MSE & \multicolumn{2}{c}{ Std error } \\
\hline & Coef. & 0.0285385 \\
\hline Root MSE & 0.0409929 & 0.2652518 \\
Counterfactual HH dependency ratio & -0.2211533 & 0.1609124 \\
HH head female & -0.445521 & 0.026784 \\
HH head age & 0.0520047 & 0.0002666 \\
HH head age square & -0.0004042 & 0.1181928 \\
Dummy HH urban & 0.3153537 & 0.4097433 \\
Dummy HH indofijian & 0.2791577 & 0.0289334 \\
Counterfactual average adult educ & 0.1335703 & 0.0397373 \\
Interaction D_indofjian education & 0.0196563 & 0.1430405 \\
HH own agricultural land 2003 & 0.0061896 & 0.7152511 \\
Constant & 5.044976 &
\end{tabular}

Table A2

Regression results for non-migrant household income, Tonga

$\underline{\text { (Dependent variable }=\text { natural log of income })}$

\begin{tabular}{|c|c|c|}
\hline Number of obs & \multicolumn{2}{|c|}{209} \\
\hline$F(11,256)$ & \multicolumn{2}{|c|}{4.03} \\
\hline Prob > F & \multicolumn{2}{|c|}{0.000} \\
\hline R-squared & \multicolumn{2}{|c|}{0.1838} \\
\hline Adj R2 & \multicolumn{2}{|c|}{0.1383} \\
\hline \multirow[t]{2}{*}{ Root MSE } & \multicolumn{2}{|c|}{1.6287} \\
\hline & Coef. & Std error \\
\hline Counterfactual $\mathrm{HH}$ size & 0.148921 & 0.044688 \\
\hline Counterfactual dependency ratio & 0.064611 & 0.474979 \\
\hline $\mathrm{HH}$ head female & -0.834088 & 0.366299 \\
\hline $\mathrm{HH}$ head age & 0.092691 & 0.058375 \\
\hline $\mathrm{HH}$ head age square & -0.000986 & 0.000552 \\
\hline Dummy urban & 0.531283 & 0.295357 \\
\hline Dummy outer island & 0.15702 & 0.444684 \\
\hline Counterfactual \# HH with tertiary education & 0.213771 & 0.184998 \\
\hline Interaction female dummy_education & 1.030943 & 0.541518 \\
\hline Own agricultural land 2003 & 0.080675 & 0.288169 \\
\hline Interaction outer island own land & 0.2906 & 0.509959 \\
\hline Constant & 4.783033 & 1.464936 \\
\hline
\end{tabular}




\section{References}

Abbott, D. F. (2006). 'Estimation of Basic Needs Poverty Lines and Incidence of Poverty in Fiji'. Draft Final Report on Analysis of the 2002/3 Household Income and Expenditure Surveys. Suva: UNDP Pacific Sub-Regional Centre (May).

Abbott, D. F., and S. Pollard (2004). Poverty and Hardship in the South Pacific. Manila: Asian Development Bank.

Adams, R. (1989). 'Worker Remittances and Inequality in Rural Egypt'. Economic Development and Cultural Change, 38 (1): 45-71.

Adams, R. (2006). 'Remittances, Poverty, and Investment in Guatemala'. In C. Ozden and M. Schiff (eds), International Migration, Remittances and the Brain Drain. Washington, DC: World Bank, 53-80.

Adams, R., and J. Page (2005). 'Do International Migration and Remittances Reduce Poverty in Developing Countries ?’ World Development, 33 (10): 1645-69.

Ahlburg, D. (1991). 'Remittances and their Impact: A Study of Tonga and Western Samoa'. Pacific Policy Paper 7. Canberra: NCDS-ANU.

Ahlburg, D. (1995). 'Income Distribution and Poverty in Fiji'. Suva: ESHDP/UNDP. Mimeo.

Ahlburg, D. (1996). 'Remittances and the Income Distribution in Tonga' Population Research and Policy Review, 15 (4): 391-400.

Asian Development Bank (ADB) (2004). Priorities of the People: Hardship in Tonga. Manila: ADB.

AusAID (2006). Pacific 2020: Challenges and Opportunities for Growth. Canberra: AusAID.

Barham, B., and S. Boucher (1998). 'Migration, Remittances, and Inequality: Estimating the Net Effects of Migration on Income Distribution'. Journal of Development Economics, 55 (2): 307-31.

Brown, R. P. C. (1995). 'Hidden Foreign Exchange Flows: Estimating Unofficial Remittances to Tonga and Western Samoa'. Asian and Pacific Migration Journal, 4 (1): 35-68.

Brown, R. P. C., and J. Connell (1993). Migration and Remittances in Tonga and Western Samoa, Vol.1: Main Report. Bangkok: ILO Regional Office for Asia and Pacific.

Brown, R. P. C., J. Connell, E. Jimenez, and G. Leeves (2006). 'Cents and Sensibility: the Economic Benefits of Remittances'. In At Home and Away: Expanding Job Opportunities for Pacific Islanders through Labour Mobility. Washington, DC: World Bank.

Cameron, J. (1983). 'The Extent and Structure of Poverty in Fiji and Possible Elements of a Government Anti-poverty Strategy in the 1980s. Discussion Paper 145. Norwich: University of East Anglia.

Chung, M. (1998). 'The Fiji Poverty Report’. Pacific Economic Bulletin, 13 (2): 133-36. 
Connell, J. (1981). 'Migration and Remittances and Rural Development in the South Pacific'. In G. W. Jones and H. R. Richter (eds), Population Mobility and Development, Monograph 27. Canberra: NCDS-ANU.

Connell, J., and R. P. C. Brown (2005). Migration and Remittances: A Pacific Overview. Manila: Asian Development Bank.

Deaton, A. (1997). The Analysis of Household Surveys: A Microeconometric Approach to Development Policy. Baltimore: Johns Hopkins University Press for the World Bank.

Leones, J., and S. Feldman (1998). 'Non-farm Activity and Rural Household Income: Evidence from Philippine Microdata'. Economic Development and Cultural Change, 46 (4): 789-806.

Lopez-Cordoba, E. (2004). Globalization, Migration and Development: The Role of Mexican Migrant Remittances. Washington, DC: Inter-American Development Bank.

McKenzie, D. (2006). 'Beyond Remittances: The Effects of Migration on Mexican Households'. In C. Ozden and M. Schiff (eds), In C. Ozden and M. Schiff (eds), International Migration, Remittances and the Brain Drain. Washington, DC: World Bank.

McKenzie, D., J. Gibson, and S. Stillman (2006). 'How Important is Selection? Experimental vs. Non-Experimental Measures of the Income Gains from Migration?' IZA Discussion Paper 2087. Bonn: IZA.

Massey, D., L. Goldring, and J. Durand (1994). 'Continuities in Transnational Migration: An Analysis of Nineteen Mexican Communities’. American Journal of Sociology, 99 (6): 1492-533.

Narsey, W. (2006). Just Wages for Fiji. Lifting Workers out of Poverty. Suva: Vanuavou Publications and ECREA.

Rodriguez, E. (1998), 'International Migration and Income Distribution in the Philippines’. Economic Development and Cultural Change, 46 (2): 239.

Shankman, P. (1976). Migration and Underdevelopment: The Case of Western Samoa. Boulder: Westview Press.

Stanwix, C., and J. Connell (1995). 'To the Islands: The Remittances of Fijians in Sydney’. Asia and Pacific Migration Journal, 4 (1): 69-88.

Stark, O., and D. Levhari (1982). 'On Migration and Risk in LDCs'. Economic Development and Cultural Change, 31 (1): 191-6.

Stark, O., J. Taylor, and S. Yitzhaki (1986). 'Remittances and Inequality'. The Economic Journal, 96 (383): 722-40.

Stavenuiter, S. (1983). 'Income Distribution in Fiji: An Analysis of its Various Dimensions with Implications for Future Employment, Basic Needs and Income Policies'. WEP Research Working Paper. Geneva: ILO.

Taylor, J. (1992). 'Remittances and Inequality Reconsidered: Direct, Indirect and Intertemporal Effects’. Journal of Policy Modelling, 14 (2): 187-208. 
Taylor, J., and T. Wyatt (1996). 'The Shadow Value of Migrant Remittances, Income and Inequality in a Household-Farm Economy'. The Journal of Development Studies, 32 (6): 899-912.

Taylor, J., S. Rozelle, and A. de Brauw (2003). 'Migration and Incomes in Source Communities: A New Economics of Migration Perspective from China'. Economic Development and Cultural Change, 52: 75-101.

UNDP (1996). Fiji Poverty Report. Suva: Government of Fiji and UNDP.

UNDP (1997). Fiji Poverty Report: A Summary. Suva: Government of Fiji and UNDP.

Walsh, C. (2002). 'Poverty in Fiji Islands and the Pacific Islands'. In C. Edmonds and S. Medina (eds), Defining an Agenda for Poverty Reduction, Vol. 1 Manila: ADB, 330-46.

Yang, D., and C. Martinez (2006). 'Remittances and Poverty In Migrants' Home Areas: Evidence from the Philippines’. In C. Ozden and M. Schiff (eds), In C. Ozden and M. Schiff (eds), International Migration, Remittances and the Brain Drain. Washington, DC: World Bank.

Yari, M. (2003). 'Beyond "Subsistence Affluence": Poverty in Pacific Island Countries'. In Bulletin on Asia-Pacific Perspectives 2003-2004: Asia-Pacific Economies, Maintaining Dynamism.. Bangkok: UN/ESCAP, 41-54. 